\title{
Society for palliative radiation oncology: report from the Eighth Annual Meeting (2021)
}

\author{
Jordan Hill ${ }^{1}$, Candice Johnstone ${ }^{2}$, Emily Martin ${ }^{3}$, Timur Mitin ${ }^{4}$, Yolanda D. Tseng ${ }^{5}$, Charles B. Simone II \\ ${ }^{1}$ Department of Radiation Oncology, University of Alberta, Edmonton, Alberta, Canada; ${ }^{2}$ Department of Radiation Oncology, Medical College of \\ Wisconsin, Milwaukee, WI, USA; ${ }^{3}$ Department of Medicine, David Geffen School of Medicine, University of California, Los Angeles, CA, USA; \\ ${ }^{4}$ Department of Radiation Medicine, Knight Cancer Institute, Oregon Health and Science University, Portland, OR, USA; ${ }^{5}$ Department of Radiation \\ Oncology, University of Washington, Seattle, WA, USA; ${ }^{\circ}$ New York Proton Center, New York, NY, USA \\ Correspondence to: Jordan Hill. Department of Radiation Oncology, University of Alberta, Cross Cancer Institute, 11560 University Avenue, \\ Edmonton, Alberta, T6G 1Z2, Canada. Email: jordan.hill@albertahealthservices.ca.
}

\begin{abstract}
The Society for Palliative Radiation Oncology (SPRO) is an international group of clinicians whose primary aim is to advance the field of palliative radiation oncology by promoting evidencebased palliative radiation therapy and excellence in primary palliative care through research, education, collaboration, and patient advocacy. SPRO held its $8^{\text {th }}$ Annual Meeting on November $4^{\text {th }}, 2021$ in association with the American Society for Radiation Oncology (ASTRO) $63^{\text {rd }}$ Annual Meeting. Accomplishments and goals from the prior year, including SPRO gaining official non-profit status, were discussed. Dr. Dirk Rades from University of Lubeck in Germany gave the keynote address, reviewing critical trials on spinal cord compression and encouraging collaboration on future trials. Recipients of the Lifetime Service Award and the Rising Star Award were announced and presented. This Meeting Report summarizes the proceedings of SPRO's $8^{\text {th }}$ Annual Meeting.
\end{abstract}

Keywords: Society for Palliative Radiation Oncology (SPRO); 8th Annual Meeting Report; Rising Star Award; Lifetime Service Aaward

Submitted Nov 18, 2021. Accepted for publication Dec 13, 2021.

doi: 10.21037/apm-21-3392

View this article at: https://dx.doi.org/10.21037/apm-21-3392

The Society for Palliative Radiation Oncology (SPRO) is an international group of clinicians whose primary aim is to advance the field of palliative radiation oncology by promoting evidence-based palliative radiation therapy and excellence in primary palliative care through research, education, collaboration, and patient advocacy (1). SPRO held its $8^{\text {th }}$ Annual Meeting (second consecutive virtual meeting) on November $4^{\text {th }} 2021$ in association with the American Society for Radiation Oncology (ASTRO) $63^{\text {rd }}$ Annual Meeting (2). Dr. Candice Johnstone, current SPRO President, welcomed attendees at the meeting start. Brief introductions then followed from the clinicians in attendance from countries including Canada, Germany, and the United States (Figure 1). Dr. Johnstone updated members on SPRO's new non-profit status, which allows SPRO to collects dues that will fund running the Society and its mission. Options on how to pay annual dues were also reviewed, in addition to goals from SPRO's previous Annual Meeting (3).

Dr. Johnstone then reviewed the term limits and procedures for elected officers on the SPRO executive committee, including president, vice president, treasurer, and secretary. Society members were reminded that the 2-year term limit will expire next year. Dr. Johnstone, the current President, will become Immediate Past President; Dr. Emily Martin, the current Vice President, will transition to the newly appointed President of SPRO. Members of SPRO were encouraged to apply for the newly vacant officer roles including secretary, treasurer, and vice president. Nomination forms will be sent out to all SPRO members in the coming months for nominations for these positions. Members were also encouraged to apply for roles in each of 


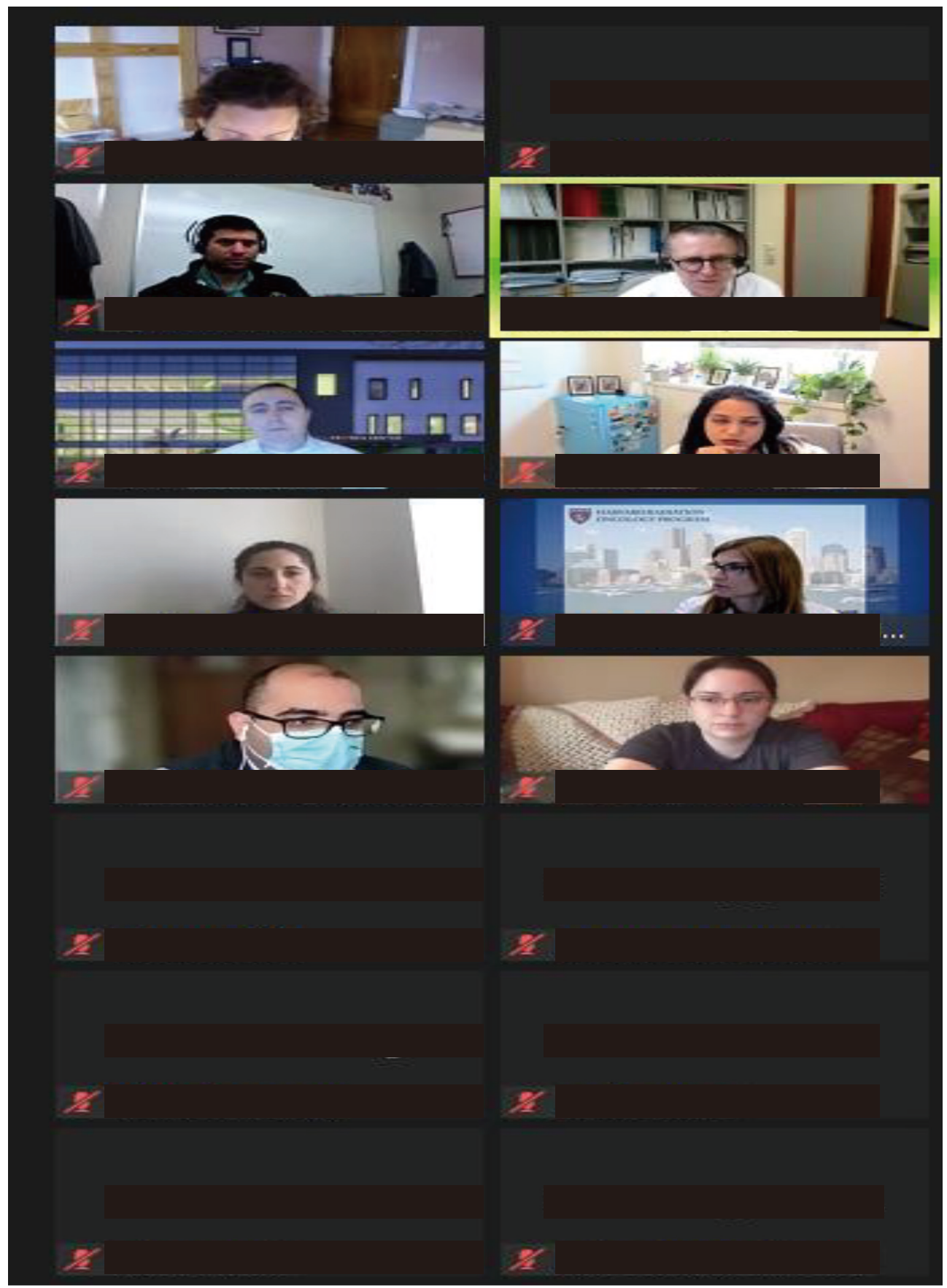

Figure 1 SPRO attendees on ZOOM.

Table 1 Awards presented at the 2021 Society for Palliative Radiation Oncology/SPRO Annual Meeting

\begin{tabular}{ll}
\hline 2020 Awards & Recipient \\
\hline Lifetime Achievement Award & Dr. Edward Chow, MD \\
Rising Star Award & Dr. Divya Yerramilli, MD \\
\hline
\end{tabular}

our five committees including the Annual Meeting, Awards, Membership, Finance, and Communications Committees.

Dr. Tracy Balboni presented Dr. Divya Yerramilli with the Rising Star Award (Table 1, Figure 2). This award is bestowed upon an individual who has made significant contributions to the field of palliative radiation oncology 


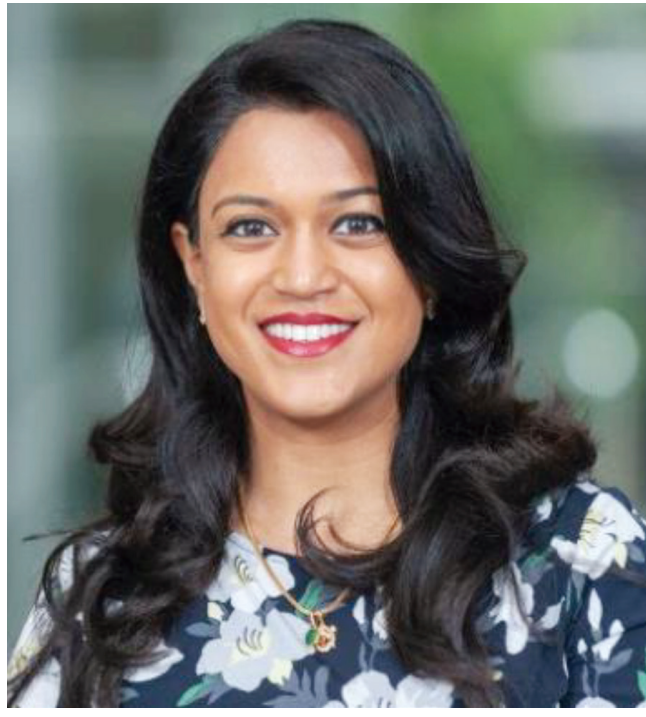

Figure 2 Dr. Divya Yerramilli, MD, 2021 Rising Star Award Recipient.

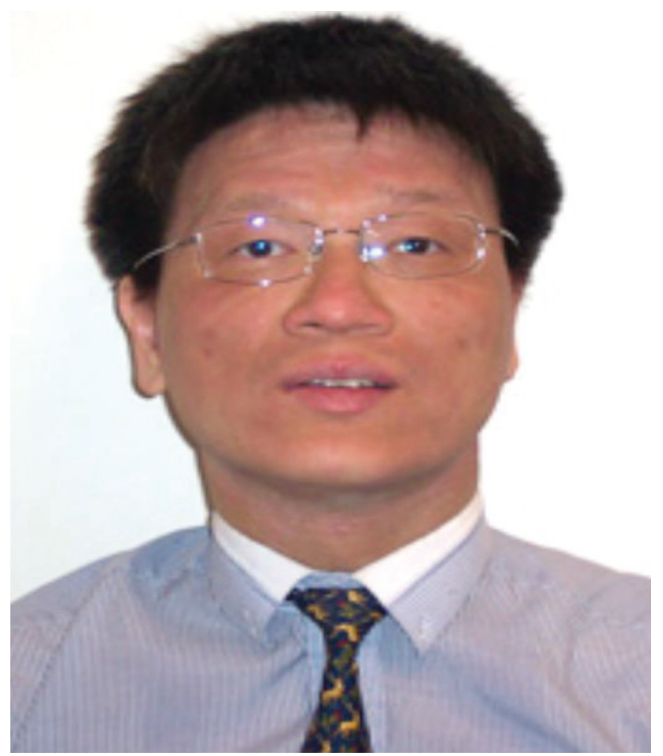

Figure 3 Dr. Edward Chow, MD, 2021 Lifetime Achievement Award Recipient.

at an early stage of their career. Dr. Yerramilli graduated from Perelman School of Medicine at the University of Pennsylvania, where she also received a Masters of Bioethics. After an internal medicine internship at Pennsylvania Hospital, she completed her radiation oncology residency at Harvard University in 2019 and joined Memorial Sloan Kettering Cancer Center (MSKCC) as an Assistant Professor. One of her first tasks at MSKCC was to develop a palliative radiotherapy service. She currently acts as the Co-Director of the inpatient radiation oncology consult (IROC) service. In addition to her clinical contributions, Dr. Yerramilli is also well known for her academic contributions to the field of palliative radiation oncology. Her research transcends many topics from surveillance after palliative radiotherapy (4) to stereotactic body radiation therapy for bone metastases (5), but she is perhaps best known for her research in medical ethics in palliative care (6). Her research ensures that patients have a good understanding of their treatment options (informed consent) and the power to make their own treatment decisions (autonomy). She has authored 18 peer reviewed publications and presented her work at multiple national conferences. She is the fourth recipient of this prestigious SPRO award.

Dr. Tracy Balboni then presented Dr. Edward Chow with the Lifetime Achievement award (Table 1, Figure 3). This award is given to an individual who has made transformative contributions to the field of palliative radiotherapy over the course of their career. Dr. Chow was nominated for this award as a result of his immeasurable contributions to education, research, and mentorship in the field of palliative radiotherapy over his illustrious career. Dr. Chow is currently a full professor at the University of Toronto, Sunnybrook campus. He has a MBBS, from the University of Hong Kong, Masters of Science from the University of Toronto, and a $\mathrm{PhD}$ from the University of Toronto. He is internationally renowned for his work in palliative radiotherapy, and he has authored countless peer reviewed publications. He has led large, randomized trials on single versus multiple fraction reirradiation for bone metastases (7) and for the use of dexamethasone prophylaxis for radiation-induced pain flare (8), and he led one of the most comprehensive and widely cited systemic reviews in palliative radiotherapy on bone metastases (9). He has also been a mentor to many aspiring radiation oncologists. Dr. Chow's palliative radiotherapy service at Sunnybrook is the gold standard and has been modelled by several other notable institutions such as Harvard and MSKCC. He is known by his colleagues to be humble and kind despite his many accolades and achievements. He is the fourth recipients of SPRO's most prestigious award.

Dr. Chuck Simone, Editor-in Chief of Annals of Palliative Medicine $(A P M)$, highlighted recent accomplishments of $A P M$. Since the Journal's inception in 2012, it has become indexed in PubMed, Medline, Scopus, and SCIE. The 
Favorable survival prognosis:

- RT alone: Longer-Course RT (better local control)

- Dose Escalation with High-Precision RT (RAMSES)?

Intermediate survival prognosis:

- Longer-Course RT or 5×5 Gy with High-Precision RT

Poor / Very Poor survival prognosis:

- Short-Course RT/Single-Fraction RT

IF-Recurrence: - Re-RT after Short-Course RT

- Surgery or HP-RT after Longer-Course RT

SBRT: - Mainly for Painful Spinal Metastases (Trials)

- constraints must be considered!

- Cave: Adjacent-Level Tumor Progression

Figure 4 Treatment approaches for metastatic spinal cord compression from Dr. Rades' keynote presentation.

Journal continues to increase its notoriety each year and has doubled its impact factor over the last two years, from 1.262 in 2018 at the time of its first impact factor (10) to now 2.595 in 2020. Following recently instituting reporting guidelines checklists and increased transparency in the peer review process (11), Dr. Simone also discussed that the journal became a monthly publication in 2021 in response to the increase in manuscript submissions to $A P M$ and to ensure that articles are published quickly to allow for impactful and potentially practice-changing research to be available to readers as soon as possible after manuscript acceptance (12). $A P M$, which is the official journal of SPRO, includes a Palliative Radiotherapy Column, which is co-edited by Drs. Edward Chow and Candice Johnstone.

Dr. Dirk Rades, Professor and Chair of the Radiation Oncology Department at the University of Lubeck Germany, gave the featured presentation on metastatic spinal cord compression (MSCC). His presentation reviewed the history, epidemiology, presentation, work up, and evolution of treatment for MSCC. Dr. Rades reviewed the literature of common dose and fractionation schedules and techniques for MSCC. He concluded his talk with a concise summary of his treatment approach for MSCC patients based on prognosis and various clinical scenarios (Figure 4). After the question-and-answer segment for his talk was completed, Dr. Rades advocated for greater collaboration between SPRO members on active and future clinical trials; he is currently enrolling patients onto RAMSES-01, a phase 2 study of patients with MSCC and favorable prognoses that are treated with $2.33 \mathrm{~Gy} \times 18$ fraction or $2.63 \mathrm{~Gy} \times 15$ fraction using a VMAT technique. He solicited collaborations among SPRO members, specifically to create a retrospective, historical control group of similar patients treated with $3 \mathrm{~Gy} \times 10$ fractions.

The SPRO Annual Meeting then concluded with the reminder that a call for nominations for next year's Lifetime Service and Rising Star Award recipients would be initiated in the coming months and announced in the summer of 2022. Members were also re-encouraged to apply for the Officer positions and Committee positions. SPRO hopes to return to having an in-person meeting in the fall of 2022 pending ongoing restrictions from the COVID-19 Pandemic.

\section{Acknowledgments}

Funding: None.

\section{Footnote}

Conflicts of Interest: All authors have completed the ICMJE uniform disclosure form (available at https://dx.doi. org/10.21037/apm-21-3392). CJ serves as the Chair of Palliative Radiotherapy Subcommittee of Annals of Palliative Medicine from July 2021 to June 2023. CBS serves as the Editor-in-Chief of Annals of Palliative Medicine. The other authors have no conflicts of interest to declare.

Ethical Statement: The authors are accountable for all aspects of the work in ensuring that questions related to the accuracy or integrity of any part of the work are appropriately investigated and resolved.

Open Access Statement: This is an Open Access article distributed in accordance with the Creative Commons Attribution-NonCommercial-NoDerivs 4.0 International License (CC BY-NC-ND 4.0), which permits the noncommercial replication and distribution of the article with the strict proviso that no changes or edits are made and the original work is properly cited (including links to both the formal publication through the relevant DOI and the license). See: https://creativecommons.org/licenses/by-nc-nd/4.0/.

\section{References}

1. Wei R, Simone CB 2nd, Lutz S. Society for palliative radiation oncology: founding, vision, and report from the Second Annual Meeting. Ann Palliat Med 2016;5:74-5.

2. Zietman A (ed). Proceeding of the American Society for Radiation Oncology Annual Meeting 2021. Int J Radiat 
Oncol Biol Phys 2021;111:Suppl Page A6.

3. Johnstone C, Martin EJ, Mitin T, et al. Society for palliative radiation oncology: report from the Seventh Annual Meeting (2020). Ann Palliat Med 2021;10:7146-50.

4. Tringale KR, Chino F, Simone CB 2nd, et al. The next unknown for patients with metastatic disease: optimal surveillance after palliative radiation therapy. Ann Palliat Med 2021;10:7153-6.

5. Gillespie EF, Lapen K, Wang DG, et al. Replacing 30 Gy in 10 fractions with stereotactic body radiation therapy for bone metastases: A large multi-site single institution experience 2016-2018. Clin Transl Radiat Oncol 2020;25:75-80.

6. Yerramilli D, Parker G, LeBaron V, et al. Ethical issues in patients referred for palliative radiation therapy. Ann Palliat Med 2019;8:231-9.

7. Chow E, van der Linden YM, Roos D, et al. Single versus

Cite this article as: Hill J, Johnstone C, Martin E, Mitin T, Tseng YD, Simone CB 2nd. Society for palliative radiation oncology: report from the Eighth Annual Meeting (2021). Ann Palliat Med 2021;10(12):13030-13034. doi: 10.21037/apm-21-3392 multiple fractions of repeat radiation for painful bone metastases: a randomised, controlled, non-inferiority trial. Lancet Oncol 2014;15:164-71.

8. Chow E, Meyer RM, Ding K, et al. Dexamethasone in the prophylaxis of radiation-induced pain flare after palliative radiotherapy for bone metastases: a double-blind, randomised placebo-controlled, phase 3 trial. Lancet Oncol 2015;16:1463-72.

9. Chow E, Harris K, Fan G, et al. Palliative radiotherapy trials for bone metastases: a systematic review. J Clin Oncol 2007;25:1423-36.

10. Simone CB 2nd. Annals of Palliative Medicine earns its first official impact factor. Ann Palliat Med 2019;8:352-4.

11. Simone CB 2nd. Innovative enhancements for Annals of Palliative Medicine. Ann Palliat Med 2020;9:E1-3.

12. Simone CB 2nd. Annals of Palliative Medicine is now published monthly. Ann Palliat Med 2021;10:1-2. 